\title{
Gastrointestinal parasitic infections in children aged less than 5 years in Ouagadougou, Burkina Faso
}

\author{
Arsène W Zongo ${ }^{1,2}$, Abdoul Karim Ouattara ${ }^{1,2 *}$, Albert Théophane Yonli ${ }^{1,2}$, Pegdwendé A Sorgho ${ }^{1,2}$, Serge Théophile Soubeiga ${ }^{1,2}$, Florencia \\ Wendkuuni Djigma ${ }^{1,2}$, Hassanata Millogo ${ }^{1}$ and Jacques Simporé ${ }^{1,2,3}$ \\ ${ }^{1}$ Laboratory of Molecular Biology and Molecular Genetics (LABIOGENE) UFR/SVT, University Ouaga I Prof Joseph KI-ZERBO, Burkina Faso \\ ${ }^{2}$ Biomolecular Research Center Pietro Annigoni (CERBA), BP 364 Ouagadougou 01, Burkina Faso \\ ${ }^{3}$ Saint Camille Hospital of Ouagadougou (HOSCO), BP 444 Ouagadougou 01, Burkina Faso
}

\begin{abstract}
Background: Parasitic gastroenteritis is a public health problem in Burkina Faso. However, there is lack of epidemiological data for better management of the disease. This study aimed at identifying the intestinal parasites responsible for diarrhoea and assessing their prevalence among children aged $0-5$ years in Ouagadougou, Burkina Faso

Methods: This hospital-based cross-sectional study consisted of 317 children aged from 0 - 5 years, with gastrointestinal disorders, were recruited at Saint Camille Hospital of Ouagadougou (HOSCO) and Notre Dame de Fatima Reception Centre (CANDAF). Stool samples were collected and processed by direct microscopic examination for the presence of intestinal parasites.

Results: An overall prevalence of 20.8\% (66/317) of parasitosis was observed. Giardia intestinalis, Entamoeba histolytica/dispar, Entamoeba coli, Trichomonas intestinalis and Hymenolopis nana species were found with respective frequencies of $12.0 \%$ (38/317), 4.4\% (14/317), 4.4\% (14/317) and 3.5\% (11/317). Children aged 25 to 60 months were the most affected by parasitosis with $57.6 \%$ (38/66) of cases. Approximately $19.0 \%$ (60/317) of the patients presented with diarrhoea. Children aged 12 to 24 months were the most affected and represented 65\% (39/60) of diarrheal cases. The most etiologic agents of diarrhoea were Giardia intestinalis and Entamoeba bistolyticaldispar found in $15 \%$ of cases.
\end{abstract}

Conclusions: Parasites were weakly associated with childhood gastroenteritis which mainly affects children under 2 years.

\section{Background}

Intestinal parasitosis caused by protozoa and helminths is one of the leading causes of childhood morbidity and mortality worldwide $[1,2]$ and they can lead to malnutrition, anemia, decreased resistance to infection, diarrhoea and stunting [3-5]. Burkina Faso faces these endemic parasitic infections. However, there is scarcity of data on the epidemiology of parasitic diseases. This study aimed to identify intestinal parasites responsible for diarrhea and evaluate their prevalence among children from 0-5 years in the city of Ouagadougou for the development of integrated and effective control strategies.

\section{Methodology}

\section{Patients and study setting}

A cross-sectional study to diagnose parasitic infections in children under 5 years old was performed at Biomolecular Research Center Pietro Annigoni/Laboratory of Molecular Biology and Genetics (CERBA/LABIOGENE). The study was conducted from June to October 2015 and included 317 stool samples of children under 5 years old from the city of Ouagadougou and attending HOSCO and CANDAF. Stool samples were collected from patients with gastrointestinal disorders. A parasitological examination of stool specimens by a clinician was requested during the study period.

\section{Stool collection and processing}

The stools of the patients, freshly emitted, were collected in a sterile container and sent directly to the medical parasitology laboratories of HOSCO and CANDAF to be examined within one hour of their emission. The stool was first examined macroscopically and analyzed for consistency, presence of blood or mucus, and the possible presence of Taenia rings, Ascaris adults, or pinworms. The fresh fecal samples were then processed by direct wet smear followed by iodine staining and examined via microscopy for the presence of the vegetative, living and mobile forms of protozoa and their cysts, but also the eggs or adult helminths. The Motic BA300 optical microscope (Motic Instruments, Canada) was used for the analysis.

\section{Statistical analysis}

The data was entered on Microsoft Excel 2016 and analyzed using the Standard Statistical Package for Social Sciences (SPSS) version 20.0.

${ }^{*}$ Correspondence to: Abdoul Karim Ouattara, Ph.D. in Molecular Biology and Genetics; CERBA/LABIOGENE, UFR/SVT, University Ouaga 1 Prof. Joseph KiZerbo, 01 BP 364, Ouagadougou 01, Burkina Faso, Tel: 226 25361232; E-mail: ak.ouattara02@gmail.com

Key words: intestinal parasites, diarrhoea, children, Burkina Faso

Received: December 27, 2018; Accepted: January 17, 2019; Published: January 21,2019 
For analysis purposes, patients were divided into 3 classes by age: 2 to 11 months, 12 to 24 months, 25 to 60 months. The qualitative variables were described in terms of size and percentage of data. The chisquare test at $5 \%$ significance level was used to compare the different proportions.

\section{Ethical considerations}

The institutional ethics committees of Saint Camille Hospital of Ouagadougou and the Pietro Annigoni Biomolecular Research Center approved this study. The objectives of the study were orally explained to the parents or legal guardians of the children in their language of comprehension. All patients provided a voluntary, signed and dated informed consent, or fingerprint if illiterate, prior to enrollment in the cohort. Parasitological examination results were immediately transmitted to the clinician for patients management.

\section{Results}

\section{Sociodemographic characteristics of the study population}

The present study consisted of 317 children aged 2 to 60 months from Ouagadougou and surrounding areas. Children aged 12 to 24 months accounted for $46.4 \%$ (147/317) of the study population (Table $1)$.

\section{Clinical characteristics of the study population}

The clinical signs that prompted the demand for parasitological examination in patients were mainly abdominal pain, vomiting, fever, constipation, anorexia, nausea and diarrhea. Diarrhea, defined as the emission of at least 3 liquid or soft stools per day, was present in $18.9 \%$ (60/317) of patients. Children aged 12 to 24 months were the most affected age group for diarrhea which represents 65\% (39/60) of cases (Table 1). An abnormal bacterial flora was found in $89.6 \%(284 / 317)$ of children with predominance in those aged 12 to 24 months (Table 2). In cases of diarrhea, we found an abnormal bacterial flora in $91.7 \%$ $(55 / 60)$ and children aged 12 to 24 months presented the majority of cases that was $65.5 \%(36 / 60)$.

The study also found a strong association $(\mathrm{p}<0.0001)$ between the presence of parasitosis and abnormal bacterial flora in cases of diarrhea. In fact, $100 \%(21 / 21)$ cases of parasitic infections among cases of diarrhea, have also presented an abnormally constituted bacterial flora.

\section{Prevalence of intestinal parasitosis}

The overall prevalence of parasitosis was $20.8 \%$ (66/317). The parasites encountered during the study period were: E. histolytical dispar, E. coli, G. intestinalis, T. intestinalis and H. nana. The prevalence of protozoa E. histolytica/dispar, E. coli, G. intestinalis and T. intestinalis was $4.4 \%$ (14/317), 4.4\% (14/317), 12.0\% (38/317) respectively. H. nana representing helminths had a prevalence of $0.3 \%(1 / 317)$ in our study population. Children aged 25 to 60 months were the most affected by parasitosis with $57.6 \%(38 / 66)$ of cases (Table 3$)$. The overall prevalence of parasitosis in diarrhea cases was 35\% (21/60). The etiology of diarrhea was in favor of E. histolytica/dispar, E. coli, G. intestinalis, T. intestinalis with respective prevalence of $6.7 \%$ (4/60), 15\% (9/60), 8.3\% $(5 / 60)$ and $5 \%(3 / 60)$ (Table 3). Parasitic co-infections were recorded at a rate of $15.1 \%(10 / 66)$ (Table 4$)$.

\section{Discussion}

This hospital-based cross-sectional study involved 317 stool specimens from children under 5 years old with gastrointestinal disorders. The results showed an overall prevalence of $20.8 \%$ of parasites with a predominance of $G$. intestinalis accounting for $57.6 \%(38 / 66)$ of parasitosis with a global prevalence of $12.0 \%$ in the study population. E. histolytica/dispar accounted for $21.2 \%(14 / 66)$ of parasitosis with a prevalence of $4.4 \%$. These results are higher than those found by Simpore et al. with $17.0 \%$ of parasitosis in 2009 including $7.6 \%$ and $1.1 \%$ of G. intestinalis and E. histolytica/dispar infections respectively in a study population of 648 children under 5 years of age in Ouagadougou [6]. In the same year, Koueta et al. recorded a prevalence of $9.7 \%$ of parasites with $2.9 \%$ and $1 \%$ of G. intestinalis and E. histolytica/dispar infections respectively in a sample of 196 children under 5 years at the Pediatric Teaching Hospital Charles de Gaule of Ouagadougou [7].

The results of the present study confirm previous observations that G. intestinalis is the first cause of parasitic gastroenteritis in Burkina Faso, followed by E. histolytica/dispar [8-11]. The overall prevalence of parasitosis (20.8\%) in our study is low compared to those found by Karou et al. (25.9\%) and by Ouermi et al. (44.3\%) [9,12]. This allows us to conclude that there has been a significant decrease in the occurrence

Table 1. Sociodemographic characteristics of the study population

\begin{tabular}{|c|c|c|c|c|c|c|}
\hline Characteristics & \multicolumn{2}{|c|}{ Male } & \multicolumn{2}{c|}{ Female } & \multicolumn{2}{c|}{ Diarrheal cases } \\
\hline Age (months) & N & \% & N & \% & N & \% \\
\hline $\mathbf{0 - 1 1}$ & 45 & 14.2 & 35 & 11.0 & 13 & 21.7 \\
\hline $\mathbf{1 2}-\mathbf{2 4}$ & 78 & 24.6 & 69 & 21.8 & 39 & 65.0 \\
\hline $\mathbf{2 5}-\mathbf{6 0}$ & 48 & 15.1 & 42 & 13.3 & 8 & 13.3 \\
\hline Total & 171 & $\mathbf{5 3 . 9}$ & 146 & $\mathbf{4 6 . 1}$ & 60 & 100.0 \\
\hline
\end{tabular}

Table 2. Macroscopic and microscopic characteristics of stool

\begin{tabular}{|l|c|c|c|}
\hline Characteristics & Pasty & N & \% \\
\hline \multirow{3}{*}{ Consistency } & Liquid & 59 & 66.5 \\
\cline { 2 - 4 } & Molded & 0 & 18.5 \\
\cline { 2 - 4 } & Glairy & 10 & 0 \\
\hline \multirow{2}{*}{ Stool aspect } & Mucous & 35 & 3.1 \\
\hline Food debris & Bloody & 1 & 11.0 \\
\hline Yeasts & & 14 & 0.3 \\
\hline Abnormal bacterial flora & 87 & 4.4 \\
\hline Cysts & 284 & 27.3 \\
\hline Vegetative forms & 62 & 89.6 \\
\hline
\end{tabular}

Table 3. Distribution of parasites infections according to age and diarrheal cases

\begin{tabular}{|l|c|c|c|c|c|c|c|c|}
\hline & \multicolumn{3}{|c|}{$\begin{array}{c}\text { Infections by age group } \\
\text { Age (Months) }\end{array}$} & \multicolumn{4}{c|}{$\begin{array}{c}\text { Distribution in diarrheal cases } \\
\text { (N=60) } \\
\text { Age (Months) }\end{array}$} \\
\hline Parasites & $\mathbf{2 - 1 1}$ & $\mathbf{1 2 - 2 4}$ & $\mathbf{2 5 - 6 0}$ & Total & $\mathbf{2 - 1 1}$ & $\mathbf{1 2 - 2 4}$ & $\mathbf{2 5 - 6 0}$ & Total \\
\hline $\begin{array}{l}\text { E. } \text { histolytica/ } \\
\text { dispar }\end{array}$ & 3 & 1 & 10 & 14 & 1 & 0 & 3 & 4 \\
\hline E. coli & 1 & 8 & 5 & 14 & 0 & 2 & 7 & 9 \\
\hline G. intestinalis & 6 & 9 & 23 & 38 & 1 & 1 & 3 & 5 \\
\hline T. intestinalis & 0 & 2 & 9 & 11 & 0 & 1 & 2 & 3 \\
\hline H. nana & 0 & 0 & 1 & 1 & 0 & 0 & 0 & 0 \\
\hline Total & 10 & 18 & 38 & 66 & 4 & 4 & 15 & 21 \\
\hline
\end{tabular}

Table 4. Parasitic co-infections

\begin{tabular}{|l|c|c|}
\hline Parasites & N & $\%$ \\
\hline E. histolytica/dispar-E. coli & 1 & 1.5 \\
\hline E. histolytica/dispar-G. intestinalis & 2 & 3 \\
\hline E. histolytica/dispar-T. intestinalis & 1 & 1.5 \\
\hline E. histolytica/dispar-G. intestinalis-T. intestinalis & 1 & 1.5 \\
\hline G. intestinalis-T. intestinalis & 3 & 4.5 \\
\hline G. intestinalis-H. nana & 1 & 1.5 \\
\hline G. intestinalis-T. intestinalis-E. coli & 1 & 1.5 \\
\hline
\end{tabular}


of intestinal parasitosis. This decline in the frequency of parasitic gastroenteritis is attributable to the improvement of hygiene and access to clean drinking water in Ouagadougou, which has experienced rapid urbanization in recent decade.

In our study, children aged 12 to 24 months were the most affected by diarrhea with $65.0 \%$ of cases compared to $21.7 \%$ of infections in children aged 2 to 11 months. These results are different from those found by Koueta et al. who reported a frequency of $66.0 \%$ of diarrhoea in children from 0 to 12 months [7]. Orlandi et al. also reported the same results in Porto Velho, Brazil [13] and Ouermi et al. in Ouagadougou [8] observed respective frequencies of $53.3 \%$ and $47.0 \%$ of diarrhea in children from 0 to 12 months. This difference with our study is explained by the fact that children aged 12 to 24 months were the most represented in the present study population or $46.4 \%$ of children under 5 years of age.

In the present study, the diarrhea was manifested mainly in the children aged less than 2 years that was $86.7 \%$ of cases. This classic observation in pediatrics can be explained by two main reasons: immune immaturity in this age group when the antibodies transmitted by the mother are declining and poor hygiene during dietary diversification. Diarrhea, usually the symptom of a gastrointestinal infection, can be caused by bacteria, viruses or parasites. The distribution of etiologies in diarrhea showed a prevalence of bacterial flora which was abnormal in $89.6 \%$ of cases. The bacterial flora was not characterized in the present study to identify the germs responsible for diarrhea. Nevertheless, the bacterial etiology would be important in the same way as viral etiology in children's diarrhea in Burkina Faso [6,11]. G. intestinalis and E. histolytica/dispar were detected in $15 \%$ of cases of diarrhea and mostly in children 25 to 60 months.

This result is similar to that found by Georges et al. in the Central African Republic with a prevalence of $12.8 \%$ of E. histolytica from diarrhea in children 25 to 60 months of age [14]. The faecooral transmission of these parasites explains their strong presence in children over 2 years of age. Indeed, defective food hygiene at the dietary diversification time could lead to parasitic contamination in these children who walk on all fours, drink dirty water and eat the sand or bring all the objects found nearby in the mouth. Parasitic diarrhea usually rare, are only one aspect of the pathology induced by digestive parasites but can be frequent and serious in endemic areas in cases of malnutrition [15]. Similarly, the sudden fall of the immune defenses can cause parasitic diarrhea in a previously healthy carrier [16,17].

\section{Conclusion}

Parasitic gastroenteritis is a public health problem in Burkina Faso despite improved hygiene conditions and affects mainly children aged 2 to 5 years. This study confirmed that G. intestinalis and E. histolytica/ dispar remain the most common parasites causing infant gastroenteritis in Burkina Faso.

\section{References}

1. Basualdo JA, Córdoba MA, de Luca MM, Ciarmela ML, Pezzani BC, et al. (2007) Intestinal parasitoses and environmental factors in a rural population of Argentina, 2002-2003. Rev Inst Med Trop Sao Paulo 49: 251-255. [Crossref]

2. Harhay MO, Horton J, Olliaro PL (2010) Epidemiology and control of human gastrointestinal parasites in children. Expert Rev Anti Infect Ther 8: 219-234. [Crossref]

3. Checkley W, Epstein LD, Gilman RH, Cabrera L, Black RE (2003) Effects of acute diarrhea on linear growth in Peruvian children. Am J Epidemiol 157: 166-175. [Crossref]

4. Bucardo F, Nordgren J, Carlsson B, Paniagua M, Lindgren PE, et al. (2008) Pediatric norovirus diarrhea in Nicaragua. J Clin Microbiol 46: 2573-2580. [Crossref]

5. Erismann S, Shrestha A, Diagbouga S, Knoblauch A, Gerold J, et al. (2016) Complementary school garden, nutrition, water, sanitation and hygiene interventions to improve children's nutrition and health status in Burkina Faso and Nepal: A study protocol. BMC Public Health 16: 244. [Crossref]

6. Simpore J, Ouermi D, Ilboudo D, Kabre A, Zeba B, et al. (2009) Aetiology of acute gastro-enteritis in children at Saint Camille Medical Centre, Ouagadougou, Burkina Faso. Pak J Biol Sci 12: 258-263. [Crossref]

7. Koueta F, Ouedraogo SO, Dao L, Ouedraogo A, Ouedraogo R, et al. (2014) Etiologies infectieuses des diarrhées aigües de l'enfant de 0 à 5 ans au centre hospitalier universitaire pediatrique charles de gaulle (Ouagadougou, Burkina Faso). Mali Médical XXIX

8. Djeneba O, Damintoti K, Denise I, Christelle NW, Virgilio P, et al. (2007) Prevalence of rotavirus, adenovirus and enteric parasites among pediatric patients attending Saint Camille Medical Centre in Ouagadougou. Pak J Biol Sci 10: 4266-4270. [Crossref]

9. Karou SD, Sanou D, Ouermi D, Pignatelli S, Pietra V, et al. (2011) Enteric parasites prevalence at Saint Camille Medical Centre in Ouagadougou, Burkina Faso. Asian Pac J Trop Med 4: 401-403. [Crossref]

10. Nitiema LW, Nordgren J, Ouermi D, Dianou D, Traore AS, et al. (2011) Burden of rotavirus and other enteropathogens among children with diarrhea in Burkina Faso. Int J Infect Dis 15: e646-e652. [Crossref]

11. Bonkoungou IJ, Haukka K, Österblad M, Hakanen AJ, Traoré AS, et al. (2013) Bacterial and viral etiology of childhood diarrhea in Ouagadougou, Burkina Faso. BMC Pediatr 13: 36. [Crossref]

12. Ouermi D, Karou DS, Ouattara I, Gnoula C, Pietra V, et al. (2012) Prevalence of intestinal parasites at Saint-Camille medical center in Ouagadougou (Burkina Faso), 1991 to 2010. Med Sante Trop 22: 40-44. [Crossref]

13. Orlandi PP, Magalhães GF, Matos NB, Silva T, Penatti M, et al. (2006) Etiology of diarrheal infections in children of Po rto Velho (Rondonia, Western Amazon region, Brazil). Braz J Med Biol Res 39: 507-517. [Crossref]

14. Georges MC, Roure C, Tauxe RV, Meunier DM, Merlin M, et al. (2004) Diarrheal morbidity and mortality in children in the Central African Republic. Am J Trop Med Hyg 36: 598-602. [Crossref]

15. Dominique G, Madeleine FT, Dominique RL (2001) Diarrhées parasitaires: de la zone tropicale à la zone tempérée. Médecine thérapeutique/Pédiatrie 4: 22-27.

16. Gendrel D (1986) Colonisation parasitaire intestinale et malnutrition protéinocalorique. Arch F Pediatr 43: 727-730.

17. Gendrel D, Richard-Lenoble D (1989) Parasitoses et chimiothérapie en zone intertropicale, Paris.

Copyright: (C2019 Zongo AW. This is an open-access article distributed under the terms of the Creative Commons Attribution License, which permits unrestricted use, distribution, and reproduction in any medium, provided the original author and source are credited. 